\title{
Multi-source Data in the Geological Disasters Early Warning for Power-Grid
}

\author{
WenHao OU ${ }^{1+}$, Wei XIA ${ }^{2,3}$, Yang Zhi ${ }^{1}$, BinBin ZHAO ${ }^{1}$, XiangZe Fei ${ }^{1}$, Xiao Ma ${ }^{1}$ \\ ${ }^{1}$ Power transformer engineering research institute, China Electric Power Research Institute Co., Ltd., Beijing \\ ${ }^{2}$ Institute of Remote Sensing and Digital Earth, Chinese Academy of Sciences, Beijing, China \\ ${ }^{3}$ University of Chinese Academy of Sciences, Beijing, China
}

\begin{abstract}
In China, the frequent occurrences of geological disasters have negative effects on the people's production, life and many other fields. In the field of power-grid constructions, due to the long-term exposure of power-transmission lines to the natural environment, severe natural disasters, such as heavy rains, landslides, and collapses, will put power-transmission lines in great dangers, and will cause a lot of property loss. Therefore, the effective detection and the early warning of geological disasters are valid approaches to improve the governance and management of geological disasters. First of all, this paper analyzes the characteristics of the prevention and control of power-transmission lines, and then puts forward the main data affecting the early warning of geological disasters, which provides a theoretical basis for further realizing the early warning of geological disasters.
\end{abstract}

Keywords : Power-transmission lines, Geological disasters, Monitoring and warning, Multi-source data

\section{Introduction.}

The monitoring and early warning of geological disasters play an important role in power-transmission projects. Through the accurate assessment of data related to geological disasters, in can effectively improve the governance and control ability of geological disasters to power-grid and reduce the losses caused by disasters as much as possible ${ }^{[1]}$.

The prevention and control of geological disaster on power-transmission lines mainly have the following characteristics. First, the large amount of prevention and control work: Due to the long distance and a large amount of towers of power-transmission lines, the hidden danger spots of geological disasters are not concentrated in certain areas, but are relatively scattered. Besides, the individual differences are very large. It can only be disposed of separately for each risk point tower instead of intensively use prevention and control measurements. Second, high requirements of prevention and control: Although avoidance measures of geological disasters have been taken into account when the route planning and design, the line towers are a series system. After the geological disasters risks of multiple scatters are superimposed, it will have certain impact on the overall reliability of the line. Hence, even if a disaster occurs at any point, it will have a systemic impact on the entire normal power-transmission line which are hundreds to thousands kilometers. Third, high cost of prevention and control: Due to the lack of monitoring data, it is difficult to grasp the risk status of geological disasters in time, and the risks and pressures of operation and maintenance work is large. When the accumulated risks develop to a certain extent, the difficulty of large-scale thorough governance of scattered risk spots increases and the cost is huge.

\section{Main data of geological disasters monitoring for power-grid}

\footnotetext{
+ Corresponding author. Tel.: +8618611580926.

E-mail address: owhnet@163.com
} 
According to the characteristics of geological disasters prevention and control work, how to accurately predict and forecast geological disasters is the crucial content of our research. Therefore, it is necessary to accurately measure and record the rules of geological disasters and dynamics of various factors causing disasters $^{[2]}$. At present, the main detection methods of geological disasters can be divided into simple detection methods and instrument detection methods. Simple detection methods include deformation displacement monitoring method, crack relative displacement monitoring methods, and visual inspection, etc. The instrument detection method is mainly used to detect dangerous hidden spots. The rules of geological disasters include the changes of various precursor phenomena before the occurrence of geological disasters and the processes after the occurrence of geological disasters. Factors causing geological disasters include ${ }^{[3,4]}$ : 1. Meteorological factors, e.g., precipitation and temperature. 2. Terrestrial hydrological factors, e.g., water level, flow rate. 3. Marine hydrological factors, e.g., tide levels, waves. 4. Other factors, e.g., ground stress, ground temperature, topographic deformation, fault displacement, underground water level, and groundwater chemical composition. By observing and measuring the above-mentioned rules of geological disasters and various inducement, it is helpful to control the occurrence of geological disasters, improve the ability of power-transmission lines to prevent disasters so as to achieve the goal of active prevention and early emergency disposal ${ }^{[5]}$.

\subsection{Application of multi-source data in the early warning and monitoring of geological disasters for power-grid}

According to the characteristics of geological disasters in power-transmission lines, combing with current status of geological disaster warning ${ }^{[6]}$, it is necessary to investigate the hidden dangers of geological disasters and build the corresponding database during the operation stage of the power grid. The goal of the early warning and monitoring system of geological disasters for power-transmission lines is to realize the monitoring and early warning data and reporting of the geological disasters through the calculation of the early warning model based on the precipitation, topography, seismic intensity, slope, and rock and soil types $^{[7,8]}$. Therefore, the multi-source data for power-grid early warning system of geological disasters mainly have three types: 1) Precipitation, 2) Disasters susceptibility evaluation, 3) Early warning report.

\subsection{Precipitation data}

During the construction of power-transmission lines, landslides have great danger to power-lines, cause high cost of reconstruction and recovery after disasters, and huge losses because of power outages, which have a huge negative impact on people's lives. Among the precipitating factors of landslides, the rainfall is most important factor. Statistical results show that $90 \%$ landslides are directly induced by or related to rainfalls. Hence, studying the change of rainfall can provide a strong reference for the monitoring and early warning of geological disasters on power-transmission lines.

\subsection{Disaster susceptibility evaluation}

There are two types of influencing factors of geological disaster susceptibility, which are environmental factors and trigger factors. Each factor is divided into several factors as shown in Figure 1. The bottom layer, which are the different states of each factors, is not listed. 


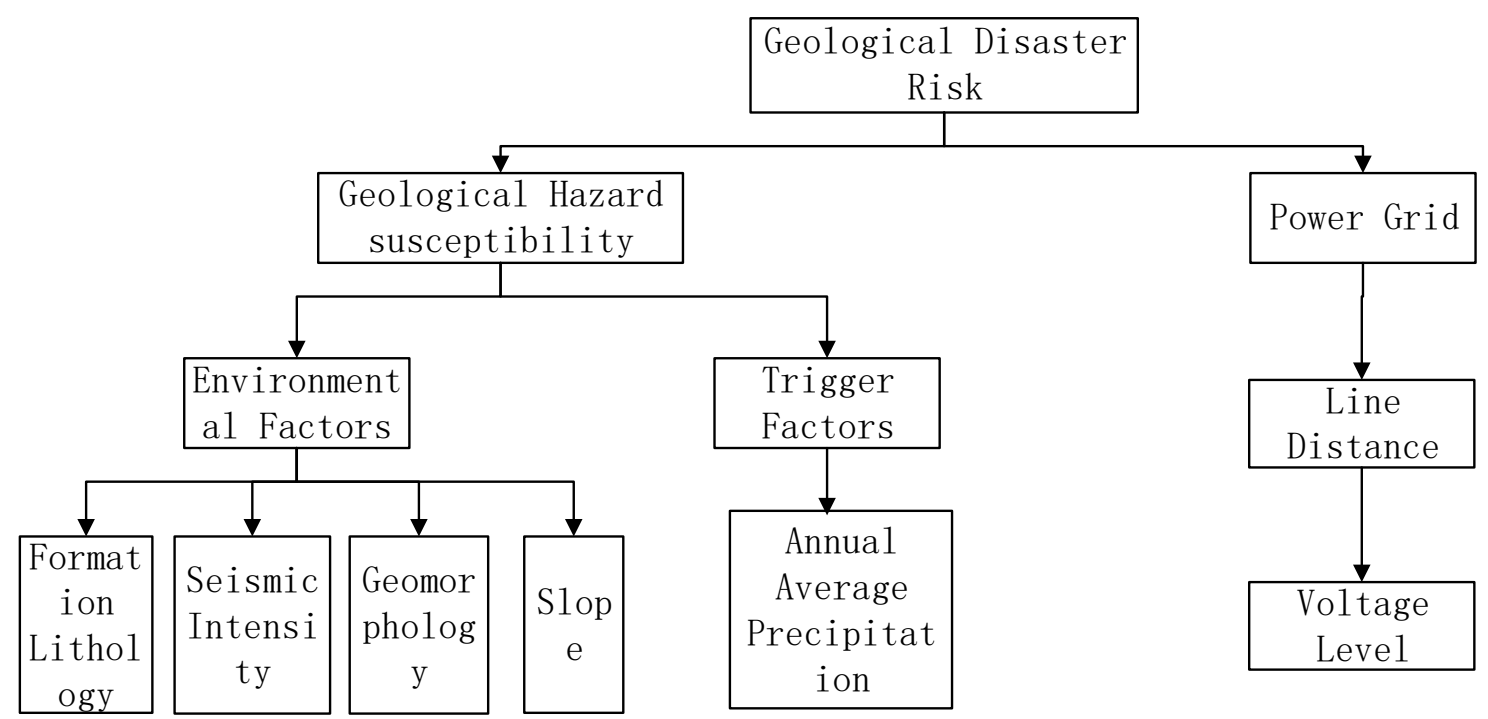

Fig 1: Hierarchical division diagram

The landslide hazard susceptibility evaluation is carried out on the site where the landslides may occur ${ }^{[9]}$. Seismic intensity, geomorphology, terrain slope, precipitation, and formation lithology were selected as factors influencing landslides. Each factor was graded by different indicators and divided into different levels. The higher the level is, the more dangerous it is. Each level corresponds to a value calculated by the weighted summation. For example, seismic factors are graded using seismic intensity. Precipitation factor are graded using annual average rainfall. The detailed factors are graded as follows:

Table 1: Grads of seismic factors

\begin{tabular}{|c|c|c|c|c|c|}
\hline Hazard level & 1 & 2 & 3 & 4 & 5 \\
\hline Seismic Intensity & $<$ VI & VI $\sim$ VII & VII $\sim$ VIII & VIII $\sim$ IX & $>$ IX \\
\hline
\end{tabular}

Table 2: Grads of geomorphology factors

\begin{tabular}{|c|c|c|c|c|c|}
\hline Level & 1 & 2 & 3 & 4 & 5 \\
\hline $\begin{array}{c}\text { Geomorpho } \\
\operatorname{logy}\end{array}$ & Plain & Hill & Mountain & Plateau & $\begin{array}{c}\text { Lower and Middle } \\
\text { Mountain }\end{array}$ \\
\hline
\end{tabular}

Table 3: Grads of slope factors

\begin{tabular}{|c|c|c|c|c|}
\hline level & 1 & 2 & 3 & 4 \\
\hline Slope $\left(^{\circ}\right)$ & $<15$ & $15 \sim 25$ & $>40$ & $25<\mathrm{Y} \leq 40$ \\
\hline
\end{tabular}

Table 4: Grads of precipitation factors

\begin{tabular}{|c|c|c|c|c|c|}
\hline Hazard Lelel & 1 & 2 & 3 & 4 & 5 \\
\hline $\begin{array}{c}\text { Annual Average Rainfall } \\
(\mathrm{mm})\end{array}$ & $<400$ & $400 \sim 800$ & $800 \sim 1200$ & $1200 \sim 1600$ & $>1600$ \\
\hline
\end{tabular}

Table 5: Grads of lithology factors

\begin{tabular}{|c|c|c|c|c|c|}
\hline Level & 1 & 2 & 3 & 4 & 5 \\
\hline $\begin{array}{c}\text { engineering } \\
\text { geological } \\
\text { petro fabric }\end{array}$ & $\begin{array}{c}\text { Loose soil, } \\
\text { Intrusive rock }\end{array}$ & $\begin{array}{c}\text { Massive } \\
\text { metamorph } \\
\text { ic rock }\end{array}$ & $\begin{array}{c}\text { extrusive rock } \\
\text { Clastic Rock }\end{array}$ & $\begin{array}{c}\text { Flaked } \\
\text { Tabular } \\
\text { metamorph } \\
\text { ic rocks }\end{array}$ & $\begin{array}{c}\text { Carbonate Rock, } \\
\text { Collapsible } \\
\text { Loess }\end{array}$ \\
\hline
\end{tabular}




\subsection{Early warning report}

The geological disaster evaluation and early warning of overhead transmission lines selects indicators such as lithology, geomorphology, slope, seismic intensity, and precipitation. Refer to the Notice of the Ministry of Land and Resources and the China Meteorological Administration on Jointly Conducting Meteorological Forecasting and Warning for Geological Disasters in Flood Season, divide the geological hazard warning into five risk levels. The classification and expression of each risk level are shown in Table 6.

Table 6 Warning risk level and presentation of geological hazard

\begin{tabular}{|l|l|l|l|}
\hline Risk Level & $\begin{array}{c}\text { Likelihood of } \\
\text { occurrence }\end{array}$ & Presentation & Lgend \\
\hline I & Very Low & Blue & \\
\hline II & Low & Green \\
\hline III & Relatively High & Yellow \\
\hline IV & High & Orange & \\
\hline V & Very High & Red & \\
\hline
\end{tabular}

According to the future 24-hour and 72-hour numerical weather forecasting, combined with internal parameters like slopes, the early warning report will generate corresponding warning layers for the shortterm and medium-term warnings of landslide area risks in reach region. Based on the regional warning results and the distribution of power-transmission lines, the UHV AC and DC lines located in the Grade IV and $\mathrm{V}$ risk sections of geological disasters and the risk levels of the key towers are listed.

\section{Conclusions}

Based on the characteristics of power-transmission lines protections, this paper analyzes the key data of geological disasters monitoring and early warning in power-grid constructions, and provides a data foundation for the monitoring and early warning system. In the construction of the monitoring and early warning system, the measured and collected activity characteristics of geological disasters and the values of various factors introducing disasters are set as the original data. These data were used by the early warning models to achieve the purpose of monitoring and warning. It can effectively improve the ability of powertransmission lines to prevent disasters, and timely make respond measurements to reduce the losses caused by natural disasters.

\section{Acknowledgements}

This work was supported by a grant from National Key R\&D Program of China (2018YFC0809400), the science \& technology project of State Grid (Research and application of special geological structure detection for transmission line corridor based on small radar, GCB17201700142), and the Academy Innovation Fund of China Electric Power Institution (5242001700FA).

\section{References}

[1] HUANG Lu,XIE Zhong, LUO Xiangang. Study on geological disaster monitoring and warning information sharing mechanism[J].Science of Surveying and Mapping,2016,41(05):55-59.

[2] WU Jifeng. Study on Multiple Information Fusion of Highway Geological Disaster Emergency and Rapid Monitoring[J]. Acta Geodaetica et Cartographica Sinica,2017,46(08):1070.

[3] WANG Longfei. Application Study of Domestic Satellite Data in The Investigation of Geological Disasters[D]. China university of geosciences(Beijing), 2014.

[4] ZHOU Daquan. Application of remote sensing technology in geological hazard monitoring[J].Information remote sensing technology, 2018(14):27-28.

[5] SU Baiyan, XU Qiang, HUANG Jian, LIANG Fan. Design and implementation of monitoring and warning system for geological disaster based on dynamic data-driven technology[J].Journal of Chengdu University of Technology(Science \& Technology Edition),2018,45(05):615-625. 
[6] ZHAO Junsan, KE Zunjie, CHEN Guoping, YUAN Lei, GU miao, WANG Tao. Implementation of the Geological Hazard Monitoring and Early Warning System Based on Multi-source Spatial Data--a Case Study of Deqing County, Yunnan Province[J].GEOMATICS WORLD,2017,24(03):35-41.

[7] CAI Lingbo, YANG Ning. Geo Information Disaster Prevention and Control System Under the Background of Big Data_ GIS Slope Monitoring and Warning Platform Based on Big Data Analysis as an Example[J].Technology and Application, 2018(14):27-28.

[8] ZHAO Haodong. Implementation of research based on large data mining supply enterprise risk project[D]. North China Electric Power University, 2017.

[9] WANG Lili, SU Cheng, FENG Cunjun, ZUO Shilei, HUANG Zhicai, ZHANG Xiaocan. A data driven selfadaptive update landslide susceptibility assessment system[J].Chinese Journal of Rock Mechanics and Engineering,2016,35(S1):3076-3083. 